\title{
Phytotreatment of Polychlorinated Biphenyls Contaminated Soil by Chromolaena odorata (L) King and Robinson
}

\author{
Raymond Oriebe Anyasi*, Harrison Ifeanyichuku Atagana \\ Department of Environmental Sciences \\ Institute for Science and Technology Education \\ University of South Africa, 1, Preller street, Muckleneuk Ridge, Pretoria, South Africa \\ 41525981@mylife.unisa.ac.za
}

\begin{abstract}
The ability of Chromolaena odorata propagated by stem cuttings and grown for six weeks in the greenhouse to thrive in soil containing different concentrations of PCB congeners found in Aroclor 1254, and to possibly remediate such soil was studied under greenhouse conditions. Chromolaena odorata plants were transplanted into soil containing 100, 200, and $500 \mathrm{ppm}$ of Aroclor in $1 \mathrm{~L}$ pots. The experiments were watered daily at $70 \%$ moisture field capacity. Parameters such as fully expanded leaves per plant, shoot length, leaf chlorophyll content as well as root length at harvest were measured. PCB was not phytotoxic to $C$. odorata growth but plants in the $500 \mathrm{ppm}$ treatment only showed diminished growth at the sixth week. Percentage increases in height of plant were 45.9, 39.4 and 40.0 for 100,200 and 500 ppm treatments respectively. Such decreases were observed in the leaf numbers, root length and leaf chlorophyll concentration. The control sample showed $48.3 \%$ increase in plant height which was not significant from the treated samples, an indication that $C$. odorata could survive such PCB concentration and could be used to remediate contaminated soil. Mean total PCB absorbed by $C$. odorata plant was between 6.40 and $64.60 \mathrm{ppm}$ per kilogram of soil, leading to percentage PCB absorption of 0.03 and $17.03 \%$ per kilogram of contaminated soil. PCBs were found mostly in the root tissues of the plants, and the Bioaccumulation factor were between 0.006-0.38. Total PCB absorbed by the plant increases as the concentration of the compound is increased. With these high BAF ensured, $C$. odorata could serve as a promising candidate plant in phytoextraction of PCB from a PCB-contaminated soil.
\end{abstract}

Keywords: Phytoremediation, Bioremediation, Soil restoration, Polychlorinated biphenyls (PCB), Biological treatment, Aroclor.

Date Received: 2013-10-03

Date Accepted: 2014-02-28

Date Published: 2014-10-03
(C) Copyright 2014 Authors - This is an Open Access article published under the Creative Commons Attribution License terms (http://creativecommons.org/licenses/by/3.0). Unrestricted use, distribution, and reproduction in any medium are permitted, provided the original work is properly cited.

\section{Introduction}

The unprecedented growth in agriculture, chemical industries, oil production, transportation, military activities and mining has contributed in the intensive generation of pollution to the environment (Graham and Ramsden, 2008). The concentrations of these anthropogenic toxic substances in the environment have risen beyond set limits; although quantification of such increases had been difficult to ascertain. However, annual estimation of the spread has been reported to be in billions of tons (USEPA, 1997). This sudden rise in waste generation leads to nature cycling and environmental degradation. Environmental degradation causes loss in biodiversity and the ecosystem which eventually impacts on human health if proper measures are not employed to address the consequences (PilonSmith, 2005; Mosaddegh et al., 2014). There are different types of contaminants found in the environment. The most dangerous among them are those that have high capabilities to persist, bioaccumulate, and be toxic to man in the food chain e.g. polychlorinated biphenyls (PCBs). Polychlorinated biphenyls (PCBs) are a family of compounds produced commercially by direct chlorination of biphenyls. As a result of its dielectric nature, the compound is used for various activities, example as a component of the transformer oil. Through its use and incessant disposal, 
PCB finds its way into the environment and its sink is the soil from where it contaminates other part of the environment (Graham and Ramsden, 2008).

Knowledge of the environmental occurrence of PCB emanated from the discovery of extremely high level of PCBs in a white-tailed sea eagle found dead in Stockholm archipelago reported by Jenson in 1966 (Andersson, 2000). Today, PCBs can be found in all environmental compartments including water, soil and air even in the Polar Regions. They spread into the environment from dumps, landfills, combustion process, and from their use in various open and close systems leading to their toxic effects in wildlife and human (Low et al., 2009). The effects of toxicity of PCB were brought to public awareness by the Yusho incident in Western Japan in 1968, where more than 1800 persons suffered from toxicity due to consumption of contaminated rice oil (Xu et al., 2010). Subsequently, the production of PCBs in Sweden and many other industrial countries have been strictly restricted since the 1970s. The most widely accepted method for the destruction of PCBs is incineration (Rodriguez and Lafuente, 2002). However, incineration is an expensive practice and often produces more toxic compounds as by-products (Andersson, 2000). Current chemical remediation techniques were developed as a result of the demerits of incineration.

The ability of PCBs to be degraded or be transformed in the environment depends on the degree of chlorination of the biphenyl molecule as well as isomeric substitution pattern (Bhandary, 2007). As a result biochemical abilities of microorganisms became one of the leading strategies in the biological treatment of PCB contaminated sites (Idris and Ahmed, 2003). This nascent shift into biological means of PCB remediation came into place because of the disadvantages of chemical and physical methods and the method is referred to as bioremediation. Bioremediation is the use of living organisms to reduce or eliminate environmental hazards resulting from accumulations of toxic chemicals or other hazardous waste (Lee, 2013). Bacteria are generally used for bioremediation, but fungi, algae and plants could also be used as is the case in this study. When plants are used in bioremediation, it is usually referred to as phytoremediation. Phytoremediation is the use of vegetation for in situ treatment of contaminants in soil and water bodies. It is a promising technique that is made up of different forms depending on the technique involved. Available research investigations into phytotreatment of PCB contaminated soil used mostly food crops, with interests in the members of the Cucurbita family (Zeeb et al., 2006; Mattina et al., 2007; Ficko et al., 2011). These however will add pressure into the already crippling world food security since such plant should not be consumed for its adversity. For phytoremediation of organic contaminants to be effective there should be maximum possession of plants phytoremediation abilities as indicated in Ficko et al, (2011). Weeds have been shown to possess such abilities which include amongst other factors the ability to be propagated and cultivated with simple agronomic measures; they are relatively inexpensive, selfsustainable, have unique root system and also have the ability to grow in a diverse environment (Singh et al., 2009).

Chlomolaena odorata (L) R.M. King \& H. Robinson (Asteraceae) is an invasive bushy shrub of Neotropical origin and has been described as one of the world's worst tropical weeds (Tanhan, 2011). The plant is a member of the tribe Eupatoreae in the sunflower family Asteraceae. Chromolaena odorata is described as a perfect competitor in its physiology; this means that it scavenges for available nutrients in the soil, as a result suppresses the growth of other plants even the weeds of its category (De Rouw, 1991).

Plants should be considered for phytoremediation studies if they possess a number of growth characteristics which include and not limited to plants ability to survive under stress, accumulates high biomass as well as the potential to dominate native vegetation at any new environment (Tanhan, 2011). Chromolaena odorata possesses most of these qualities, some of which are responsible for its success as an invasive plant in new environments. These factors therefore present Chromolaena odorata as a potential plant for phytoremediation of PCB-contaminated soil. This study involves an investigation of the capabilities of $C$. odorata plants to grow in Aroclor contaminated soil and reduce the concentration of the compound under greenhouse conditions.

\section{Materials and Methods}

Chromolaena odorata plants were transplanted directly into a $1 \mathrm{~kg}$ of soil containing different concentrations of Aroclor in PVC pots, noting the initial length and mature leaf per plant (MLPP). The experiment which was translated into treated soil with plants (T) made in three different concentrations of 100, 200 and $500 \mathrm{ppm}$ and treated soil without plants 
(control=C), was monitored for six weeks at prevailing environmental conditions, maintaining other agronomic procedures. Measurements were made over time of plant growth parameters including length of plants, MLPP, leaf colour (Chlorophyll content) and root length which was measured on the day of harvest. Harvested plant samples were analyzed for total PCB (tPCB) using GC-MS while the residual soil was analyzed to ascertain the reduction rate of PCB at the end of the experiment. They were no application of inorganic manures to the soil mixes, but animal compost was used during soil preparation. After six weeks of experimentation, the soil and plants were harvested, measured and sampled for analysis

Initial length of plant was measured on the day of contamination using strings and meter rule and subsequent measurements were taken at weekly intervals. MLPP was also measured on Day one of contamination and subsequently at weekly intervals using manual counting of the leaves. The same measurement sequence was employed in leaf chlorophyll using Chlorophyll meter from the UNISA Unit for Horticulture (SPAD-502Plus Konica Minolta, Japan-). Root length was measure first on the day of contamination and finally on the day of harvest using strings and meter rule to get the initial and final measurements respectively. Soil and plant samples were thoroughly homogenized for analysis and subsampled for the determination of wet and dry weight ratio. The samples for biomass determination were dried at $50^{\circ} \mathrm{C}$ until constant mass using Lancon industrial oven (Labcon South Africa) with heating integration of $40-100^{\circ} \mathrm{C}$ and were measured to obtain the dry mass. The dried plant samples were then ground using commercial blender, sieved at $2 \mathrm{~mm}$ and were stored prior to extraction while the soil samples were ground using a commercial mortar and was sieved at $2 \mathrm{~mm}$. The extraction process adopted was 'Soxhlet Extraction Method 3540' (US EPA, 1997), USEPA Method 3630B: for cleaning, and USEPA modified $8089 / 8081$ method was used for the determination of total PCB. The analysis was conducted according to Anyasi (2012). The whole values presented from the analyses of samples were the mean values of three replicates. General linear model of analysis of variance (ANOVA) was used at $\mathrm{P}=0.05$ level of significance difference (SPSS) (version 11.0 for windows).

\section{Results and Discussion}

The properties of the soil in which the plant was grown indicated slightly acidic clayey sandy soil, other parameters indicated compatibility with optimal growth of plants [7ppm of TOC, $\mathrm{N}=0.03 \% \mathrm{wt}, \mathrm{P}=9 \mathrm{ppm}$, $\mathrm{K}=15.5 \mathrm{ppm}, \mathrm{Ca}=83 \mathrm{ppm}, \mathrm{Mg}=1.2$, and moisture content was $4.8 \%$ ]. The low value of total nitrogen in the soil compared to carbon and phosphorus indicated the need for a nitrogen impacted manure. However, the CNP ratio of the soil in relation to the manure was 233:1:300 and 1:2:1 respectively. There was progressive growth of C. odorata throughout the duration of the study in both the treated and the control experiment. After six weeks of growth in Aroclor treated soil, there was no sign of lethal phytoxicity to $C$. odorata, except at the $500 \mathrm{ppm}$ treatments where chlorosis was observed towards the end of sixth week. Plant growth measured from the difference between the initial and final length of $C$. odorata and deduced in percentage as the percentage growth rate is as presented in Table 1.

Table 1: Percentage growth rate of $C$. odorata at different concentrations of Aroclor in soil.

$\begin{array}{cccc}\begin{array}{c}\text { Treatments } \\ \text { (ppm) }\end{array} & \begin{array}{c}\mathbf{1 0 0} \boldsymbol{\mu g} / \mathbf{m l} \\ \mathbf{( c m )}\end{array} & \begin{array}{c}\text { \% growth rates } \\ \mathbf{2 0 0} \boldsymbol{\mu g} / \mathbf{m l} \\ (\mathbf{c m})\end{array} & \begin{array}{c}\mathbf{5 0 0} \boldsymbol{\mu g} / \mathbf{m l} \\ \mathbf{( c m )}\end{array} \\ & & & \\ \mathrm{T} & 45.89 \pm 0.13 & 40.01 \pm 1.12 & 39.41 \pm 0.24 \\ \mathrm{C} & \mathrm{NP} & \mathrm{NP} & \mathrm{NP}\end{array}$

Values with the same * in the same column were not significant at $5 \%$ level according to Bonferoni test. $\mathrm{T}=$ Treatments, $\mathrm{C}=$ Control, $\mathrm{NP}=$ Not planted.

Mean percentage growth rate was highest at 100 ppm (45.9), least in 500 ppm (39.41). Meanwhile, the growth of $C$. odorata was found to be negatively correlated with increase in concentration of Aroclor in soil. Percentage growth rate at untreated control was slightly lower than that in $100 \mathrm{ppm}$ treatments, this was not significant $(\mathrm{p}=0.02)$ at $\mathrm{p}=0.05$. MLPP of $C$. odorata at any interval of time was observed to be influenced by the presence of Aroclor in its tissues. MLPP followed the same trend as seen in growth rate as well as increase in root length. At $100 \mathrm{ppm}$ MLPP increased from initial 28 leaves to final 50 leaves, leaving a mean percentage increase of 78.6. Mean percentage increases at 200 and 500 ppm were 45.1 and 24.2 respectively (Table 2). 
Table 2: Percentage change in mature leaves per plant in different concentrations of Aroclor.

\begin{tabular}{cccc}
$\begin{array}{c}\text { Treatments } \\
\text { (ppm) }\end{array}$ & \multicolumn{3}{c}{ increase in mature leaves per plant } \\
& $\mathbf{1 0 0}$ & $\mathbf{2 0 0}$ & $\mathbf{5 0 0}$ \\
& $\mathbf{( m g / \mathbf { k g } )}$ & $\mathbf{( \mathbf { m g } / \mathbf { k g } )}$ & $\mathbf{( m g / \mathbf { k g } )}$ \\
& $\mathbf{s o i l}$ & soil & soil \\
$\mathrm{T}$ & $78.57 \pm 0.43^{*}$ & $45.16 \pm 1.04^{*}$ & $24.240 .31^{*}$ \\
$\mathrm{C}$ & $\mathrm{NP}$ & $\mathrm{NP}$ & $\mathrm{NP}$
\end{tabular}

Values with the same * in the same column were significant at $5 \%$ level according to Bonferoni test. $\mathrm{T}=$ Treatments, $\mathrm{C}=$ Control, $\mathrm{NP}=$ Not planted.

Mean Percentage change in MLPP at untreated control (C1) was 86.9; this was not significant from the $100 \mathrm{ppm}$ treatments but significantly different from the 200 and 500 ppm treatments respectively. Root lengths of $C$. odorata at different concentrations of Aroclor 1254 and 1260 were equally synonymous with what was observed in growth rate and MLPP. Percentage change in root length was high at $100 \mathrm{ppm}$ (78.3), but reduced considerably at 200 and 500 ppm (59.1 and 56.1) respectively Table 3 .

Table 3: Percentage change in root length at different concentrations of Aroclor.

\begin{tabular}{cccc} 
Treatments & \multicolumn{3}{c}{ Percentage change in root length } \\
(ppm) & $\mathbf{1 0 0} \mathbf{~ p p m}$ & $\mathbf{2 0 0} \mathbf{~ p p m}$ & $\mathbf{5 0 0} \mathbf{~ p p m}$ \\
$\mathrm{T}$ & $78.28 \pm 0.33^{*}$ & $59.13 \pm 0.08$ & $56.12 \pm 0.89$ \\
$\mathrm{C}$ & $\mathrm{NP}$ & $\mathrm{NP}$ & $\mathrm{NP}$
\end{tabular}

Values with the same alphabets in superscript in the same column were significant at $5 \%$ level according to Bonferoni test. $\mathrm{T}=$ Aroclor $1254, \mathrm{C}=$ Control, NP=Not planted

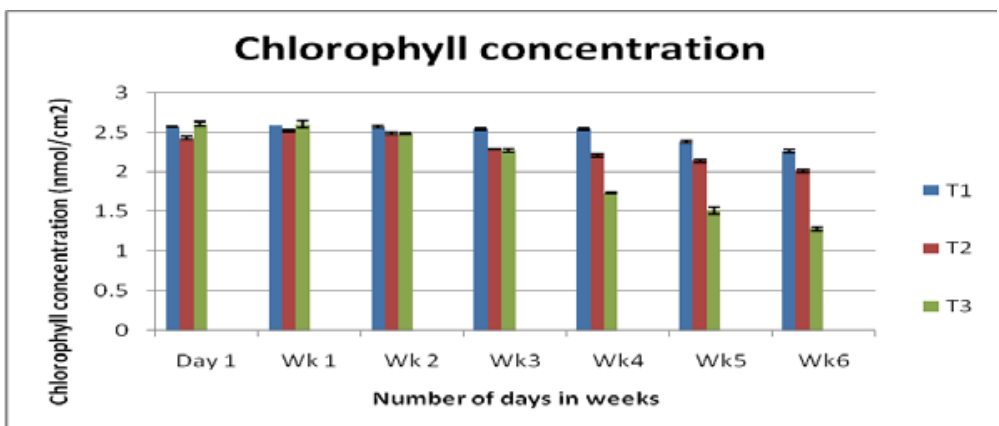

Figure 1: Leaf chlorophyll concentration showing variations in leaf color in different Aroclor concentrations over time (Error bars indicate standard error of the mean), $\mathrm{T}_{1}=\mathrm{T}$ at 100 $\mathrm{ppm}, \mathrm{T}_{2}=\mathrm{T}$ at $200 \mathrm{ppm}, \mathrm{T}_{3}=\mathrm{T}$ at $500 \mathrm{ppm}$
Table 4: Change in leaf chlorophyll concentration (Values are means of three replicates).

\begin{tabular}{cccc}
\hline Treatments & $\begin{array}{c}\text { Initial (Day } \\
\text { 1) } \\
\text { nmol/cm }\end{array}$ & $\begin{array}{c}\text { Final (Week } \\
\text { 6) nmol/cm }\end{array}$ & $\begin{array}{c}\text { Percentage } \\
\text { change in } \\
\text { chlorophyll } \\
\text { concentration } \\
\text { (\%) }\end{array}$ \\
\hline $\mathrm{T}_{100}$ & $2.57 \pm 0.02$ & $2.26 \pm 0.06$ & $12.06 \pm 0.37$ \\
$\mathrm{~T}_{200}$ & $2.43 \pm 0.14$ & $2.01 \pm 0.07$ & $17.28 \pm 0.16$ \\
$\mathrm{~T}_{500}$ & $2.60 \pm 0.11$ & $1.28 \pm 0.19$ & $50.76 \pm 0.25^{*}$ \\
$\mathrm{C}$ & $\mathrm{NP}$ & $\mathrm{NP}$ & $\mathrm{NP}$
\end{tabular}

Values with the same * in the same column were significant at $5 \%$ level according to Bonferoni test. $\mathrm{T}_{100}=$ $\mathrm{T}$ at $100 \mathrm{ppm}, \mathrm{T}_{200}=\mathrm{T}$ at $200 \mathrm{ppm}, \mathrm{T}_{500}=\mathrm{T}$ at $500 \mathrm{ppm}$, $\mathrm{C}=$ Control, $\mathrm{NP}=$ Not planted

Although the leaves of $C$. odorata at 100 and 200 ppm treatments showed no observable colour change throughout the duration of the experiment when compared with untreated control, chlorophyll measurement chart however indicated alternatively. At $100 \mathrm{ppm}$, mean initial chlorophyll measurement was $2.57 \mathrm{nmol} / \mathrm{cm}^{2}$, it increased slightly to $2.59 \mathrm{nmol} / \mathrm{cm}^{2}$ at the first week and reduced from the second week $(2.57$ $\left.\mathrm{nmol} / \mathrm{cm}^{2}\right)$ to the sixth week $\left(2.26 \mathrm{nmol} / \mathrm{cm}^{2}\right)$ Figure 1. Differences existed between chlorophyll concentration of the initial and final measurements of the chlorophyll meter; this is depicted as the change in percentage leaf chlorophyll concentration Table 4. The mean percentage change in chlorophyll throughout the six weeks of experimentation was 12.06, 17.28, 50.76, in their respective treatments $\left(\mathrm{T}_{100}, \mathrm{~T}_{200}, \mathrm{~T}_{500}\right)$. However, pale green colour change was observed at the $500 \mathrm{ppm}$ treatment towards the sixth week of experimentation as was shown by their high percentage change in chlorophyll concentration.

Phytoremediation of soil contaminants is attributed to amongst other factors to the ability of plants to grow rapidly in the contaminated soil so as to be able to exert the physiological processes involved in the translocation of the contaminants in solutes through the plants tissues. Chromolaena odorata demonstrated this characteristic by its ability to grow in the PCBcontaminated soil throughout the period of the experiment. In this experiment, PCB concentrations of 100 and $200 \mathrm{ppm}$ treatments were not phytotoxic to $C$. odorata as the plant was able to complete the growth duration of the experiment in those treatments or that 
the plant was able to manage such effects. At $500 \mathrm{ppm}$ PCB concentrations, $C$. odorata was slightly affected by phytotoxicity of the pollutant towards the sixth week of growth in the treated soil, although it completed the experimental period. PCB contamination between 0$260 \mathrm{ppm}$ has been reported not to be phytotoxic to various plants tested for its phytoremediation ability, but higher concentration of PCB was seen to cause stress to the plants (Lee, 2013; Zeeb et al., 2006; Ficko et al., 2011). The response showed by $C$. odorata towards $500 \mathrm{ppm}$ of PCB may have been the cause of the stress; it could also be attributed to other factors not measured.

\subsection{Residual PCB Recovered from the Soil and Plant}

Mean total PCB concentration in plants tissues were 6.4, 11.7 and $55.8 \mu \mathrm{g}$ for 100, 200 and $500 \mathrm{ppm}$ treatments respectively, while the control was zero. Final soil PCB concentrations were measured to be 2.06, 3.01 , and $4.05 \mathrm{ppm}$ for 100, 200, and $500 \mathrm{ppm}$ treatment concentrations respectively. At same time, the residual PCB concentration at control was 15.76 $\mathrm{ppm} / \mathrm{kg}$ of soil. Results of total PCB recovery in soil and plants tissues are presented in Table 5. PCB concentration factors also know as bioaccumulation factors (BAFs) were 0.022, 0.032, and 0.065 for the respective treatments. In author's previous unpublished study, a comparative study was set out to test the impending effects of volatilization and microorganisms in soil PCB remediation. The mean values observed were higher than the corresponding values obtained at uninhibited treatments. This shows that the inhibition of volatilization as well as microbial actions accounted for PCB retention by the soil. However, such effect was higher in former than in later, and the reduction was however, not significantly different from the reduction of the treated and planted. This is in agreement with Aslund et al., (2008), which reported that the primary uptake pathway of PCB into plants should be root uptake and possible translocation and consistent with other studies on other POP uptake in plants (Mattina et al., 2007). Other scholars have also reported on the influence of microbes on uptake of PCB by plants (Xu et al., 2010; Anyasi 2012).

Table 5: PCB recovery results: Initial soil PCB concentration, Residual soil PCB concentration, total PCB concentration, percentage PCB absorbed, percentage change in PCB, and PCB concentration factor.

\begin{tabular}{|c|c|c|c|c|c|c|}
\hline Treatments & $\begin{array}{l}\text { Initial soil } \\
\text { PCB conc. } \\
\text { (ppm) }\end{array}$ & $\begin{array}{l}\text { Final soil } \\
\text { PCB conc. } \\
\text { (ppm) }\end{array}$ & $\begin{array}{l}\text { Total PCB } \\
\text { in plants } \\
\text { tissue }(\mu \mathrm{g})\end{array}$ & $\begin{array}{c}\text { \% PCB } \\
\text { absorbed }\end{array}$ & $\begin{array}{l}\text { \% change } \\
\text { in } P C B\end{array}$ & $\begin{array}{l}\text { PCB concentration } \\
\text { factor (PCB-RF) }\end{array}$ \\
\hline $\mathrm{T} 100$ & $\begin{array}{c}10.5 \\
\pm 0.20^{*}\end{array}$ & $2.06 \pm 0.04$ & $6.40 \pm 0.12^{*}$ & $2.10 \pm 0.00$ & $80.4 \pm 0.60^{*}$ & $0.022 \pm 0.00$ \\
\hline $\mathrm{C}$ & $9.4 \pm 0.02$ & $8.50 \pm 0.11$ & NP & NP & $9.6 \pm 0.30$ & NP \\
\hline T200 & $\begin{array}{c}19.8 \\
\pm 0.00^{*}\end{array}$ & $3.01 \pm 0.02$ & $\begin{array}{c}11.70 \\
\pm 0.15^{*}\end{array}$ & $0.03 \pm 0.00$ & $84.8 \pm 0.06^{*}$ & $0.032 \pm 0.00$ \\
\hline $\mathrm{C}$ & $18.5 \pm 0.03$ & $\begin{array}{l}15.76 \\
\pm 0.13\end{array}$ & NP & NP & $14.8 \pm 0.10$ & NP \\
\hline T500 & $27.2 \pm 0.20$ & $4.05 \pm 0.08$ & $\begin{array}{l}55.80 \\
\pm 0.70^{*}\end{array}$ & $11.98 \pm 0.12^{*}$ & $85.1 \pm 0.20^{*}$ & $0.065 \pm 0.00^{*}$ \\
\hline $\mathrm{C}$ & $\begin{array}{c}18.5 \\
\pm 0.20^{*}\end{array}$ & $5.76 \pm 0.00$ & NP & NP & $14.8 \pm 0.00^{*}$ & NP \\
\hline
\end{tabular}

Values with the same $*$ in the same column were significant at $5 \%$ level according to Bonferoni test. $\mathrm{T}=$ Aroclor 1254, C=Control, NP=Not planted

\subsection{Total PCB Recovered from Plant}

Absorption of PCB by C. odorata occurred mostly at the root tissues of the plant. For example at $100 \mathrm{ppm}$, the concentration of PCB in the root was found to be $0.22 \mu \mathrm{g} / \mathrm{g}$ of soil with a total root biomass of 
$7.25 \mathrm{~g}$, resulting to a total root PCB of $1.6 \mu \mathrm{g}$. Although the stem and leaf biomass were above $10 \mathrm{~g}$ respectively which was higher than what was obtained in the root, the total PCB in both the stem and leaf was still not applicable because there was no PCB dictated in the stem and leaf tissues. Total PCB concentrations found in the tissues of $C$. odorata, ranges from 3.1 to $64.6 \mathrm{ppm}$, the value was seen to increase as the concentration of the treatment was increased. This is in agreement with the study of Pinsker, (2011), which reported that initial soil PCB has a great effect on the amount of PCB absorbed by plants, its translocation as well as the concentrations of the residual PCB in the soil at the end of a phytoremediation study. There was percentage reduction of PCB concentration from 80.4 to 86.6 within the six weeks of experiment. These values are appreciable when compared with the mean reduction of PCB per month of other plants species that were used for various PCB phytoremediation studies. The mean PCB reductions were reported to be in the range of 0.1 $14.8 \%$ (Dzantor et al., 2000; Ficko et al., 2010). Although total PCB concentration in most of the plant tissues of the Aroclor-treated experiments was not applicable, there was still reduction in the amount of PCB in soil at the end of the experiments. Such effect was also observed in the unplanted control samples (C2=14.8\%) and could be attributed to natural attenuation and perhaps other parameters not measured.

\subsection{PCB Reduction in the Soil after Six Weeks of Growth with $C$. Odorata}

Highest reduction in PCB concentration was found in soil with $500 \mathrm{ppm}$ concentrations as observed in $\mathrm{T}_{200}, \mathrm{~T}_{500}, \mathrm{C} 4$ and $\mathrm{C} 3$ where they was reduction of PCB of about 85.1, 84.8, 84.1 and $82.6 \%$ respectively. Treatment with initial concentration of $100 \mathrm{ppm}$ had percentage reduction of 80.4. However, the control sample without plant (C) only reduced by $14.8 \mathrm{ppm}$, this may have been aided by nature (Table 5). In this study, greater amount of PCB found in the plants tissue were concentrated in the roots, it could be as a result of the diffuse root system of the plant; an importance feature of any phytoremediation plant. Total root concentrations of PCB were reported to be in the range of 0.26-17.85 ppm (Result not shown). Increased root concentration of PCB leads to a synonymous increase in bioaccumulation factors (BAF). Bioaccumulation factor determines plants ability to accumulate and concentrate a greater quantity of PCBs than the surrounding soil. This phenomenon is important as it provides one with the idea on how to measure the ability of plants to draw PCB towards the roots when it absorbs water and nutrients from the soil known as imbibition. The measurement of BAF in $C$. odorata was in range of 0.01 to 0.4 which is greater than what was observed with Alfalfa by Zeeb et al., (2006), and some other studies (Low, 2009; Aslund et al., 2007/8). From this, it can be explained that $C$. odorata was able to draw PCBs towards its root with its BAF value within the range of measured value of BAF of other PCB phytoremediation plants. This generates a new interest in the use of C.odorata in the phytoextraction of PCB.

\section{Conclusions}

This study has been able to demonstrate that $C$. odorata is able to reduce the concentrations of PCB at the 100, 200 and $500 \mathrm{ppm}$ of Aroclor treated soil significantly than unplanted control. At the end of six weeks of experiment, there was sustenance of growth of the plant which causes phytotreatment of soil PCB from a PCB contaminated soil. The fact that $C$. odorata was able to survive this different contaminant regime of Aroclor, is an evident that the plant is a promising candidate for uptake of PCB from a PCB-contaminated soil and such effect could be enhanced with soil amendments (bioaugmentation) that aids microbial presence in the rhizosphere as well as growing the plants for a longer duration in the contaminated soil. The major weakness of the method that was used in this study was that the reduction of the PCB in the soil may have been aided by other factors but such was measured in the author's other unpublished study.

\section{Acknowledgement}

The South African National Research Foundation (NRF) is acknowledged for funding this project.

\section{References}

Andersson P, 2000. Physico-chemical characteristics and quantitative structure-activity relationships of PCBs. Department of Environmental chemistry, Umea University-Sweden. Pp. 1-10.

Anyasi R 0, 2012. Bioremediation of polychlorinated biphenyls (PCBs)-contaminated soil by phytoremediation with Chromolaena odorata (L) RM King and Robinson. MSc Thesis, University of South Africa. Pp. 77-78. 
Aslund M L W, Zeeb, B.A., Rutter, A. and Reimer, R. 2007. In situ phytoextraction of polychlorinated biphenyls (PCB)-contaminated soil. Science of the Total Environment, 374(1), 1-12.

Bhandary A, 2007. Remediation technologies for soil and groundwater. US Environmental Council. Science, pp. 17-23.

De Rouw A, 1991. The invasion of Chromolaena odorata (L.) King \& Robinson (ex Eupatorium odoratum) and competition with a native flora in a rain forest zone, South-west Cote d'Ivoire. Journal of Biogeography, 18: 13-32.

Ficko S A, Rutter A, Zeeb B A, 2011. Phytoextraction and uptake patterns of weathered polychlorinated biphenyls-contaminated soils using three perennial weeds species. Journal of Environmental Quality, 40: 1870-1877.

Graham C, Ramsden J J, 2008. Introduction to global warming: Complexity and security. IOS Press, pp. 147-184.

Idris A, Ahmed M, 2003. Treatment of polluted soil using bioremediation - A review. Faculty of Chemical and Environmental Engineering, University of Putra, Malaysia, pp. 1-18.

Lee J H, 2013. An overview of phytoremediation as a potential promising technology for environmental pollution control. Biotechnology and Bioprocess Engineering, 18: 431-439

Low J E, Whitefield Aslund M L, Rutter A, Zeeb B A, 2009. Effect of plant age on PCB accumulation by Cucurbita pepo ssp. pepo. Journal of Environmental Quality, 39: 245-250.

Mattina M J I, Berger W A, Eitzer B D, 2007. Factors affecting the phytoaccumulation of weathered, soil-borne organic contaminants: analyses at the ex Planta and in Planta sides of the plant root. Plant and Soil, 291: 143-54.

Mosaddegh M H, Jafarian A, Ghasemi A, Mosaddegh A, 2014. Phytoremediation of benzene, toluene, ethylbenzene and xylene contaminated air by D. deremensis and 0. microdasys plants. Journal of Environmental Health Science and Engineering, 10: $12-39$

Pilon-Smith E, 2005. Phytoremediation. Plant Biology, 56: $15-39$.

Pinsker N I, 2011. Phytoremediation of PCBcontaminated soil: Effectiveness and regulatory policy. MSc. Thesis, Virginia Commonwealth Universisty. Pp. 56-73.
Rodriguez J G, Lafuente A, 2002. A new advanced method for heterogeneous catalyzed dechlorination of polychlorinated biphenyls in hydrocarbon solvent. Tetrahedron Letters, 43: 9581-9583.

Singh S, Thorat V, Kaushik C P, Raj K, D’Souza S F, 2009. Potential for Chromolaena odorata for phytoremediation of ${ }^{137} \mathrm{Cs}$ from solution and low level nuclear waste. Journal of Hazardous materials, 162: 743-745.

Tanhan P, Pokethitiyook P, Kruatrachue M, Chaiyarat R, Upatham S, 2011. Effects of soil amendments and EDTA on lead uptake by Chromolaena odorata: Greenhouse and Field Trial Experiments. International Journal of Phytoremediation, 13: 897-911.

US EPA 1997. Method 1613, Revision B, Tetra- through octachlorinated dioxins and furans by isotope dilution HRGC/ HRMS, September 15, 1997, 40 CFR 136 (FR 48405), Washington, DC. Pp. 79.

Xu L, Teng Y, Li Z, Norton J M, Luo Y, 2010. Enhanced removal of polychlorinated biphenyls from Alfalfa rhizosphere soil in a field study: The impact of a rhizobial innoculum. Science of the Total Environment, 408: 1007-1015.

Zeeb B A, Amphlett J S, Rutter A, Reimer K J, 2006. Potential for phytoremediation of polychlorinated biphenyls-(PCB)-contaminated soil. International Journal of Phytoremediation, 8: 197-221. 